Ensino, Saúde e Ambiente - V 7 (1), Edição Especial, maio de 2014

\title{
COLORINDO BANDEIRAS - A ELABORAÇÃO DE UM SIMULADOR PARA O ESTUDO DE INDICADORES ÁCIDO-BASE
}

\section{COLORING FLAGS - THE DEVELOPMENT OF A SIMULATOR FOR THE STUDY OF ACID-BASE INDICATORS}

\author{
Eluzir P. Chacon ${ }^{1}$, Lucidéa G. R. Coutinho ${ }^{2}$ \\ ${ }^{1}$ Professora do Departamento de Química Inorgânica e do Programa de Pós-Graduação em Ensino de \\ Ciências e da Natureza da Universidade Federal Fluminense (UFF) - epchacon@ vm.uff.br \\ ${ }^{2}$ Professora do Departamento de Físico-Química e do Programa de Pós-Graduação em Ensino de \\ Ciências e da Natureza da Universidade Federal Fluminense (UFF) - lucideac@ yahoo.com
}

\section{RESUMO}

Este trabalho tem como principal objetivo relatar a elaboração de um software educacional criado para estimular o ensino/aprendizagem de indicadores ácido-base no Ensino Fundamental e Médio. Pretende-se através do simulador desenvolvido estudar este conteúdo de modo dinâmico, divertido e articulado com a Geografia e a História.

Palavras-chave: bandeiras, simulador, cor, indicadores ácido-base

\begin{abstract}
This paper aims to describe the elaboration of an educational software created to encourage the teaching/learning of acid-base indicators in primary and secondary education. It is intended through the simulator developed to study this content dynamic, fun and articulate manner with Geography and History.
\end{abstract}

Key-words: flags, simulator, color, acid-base indicators.

\section{INTRODUÇÃO}

O Ensino de Ciências na Escola Básica, dentro do qual se inclui a Química, deve ser compreendido como importante eixo de formação lógica do estudante. Neste sentido, a cultura científica entendida no Ensino Médio como os conteúdos de Química, Física, Biologia e Matemática tem a tarefa de disseminar e sedimentar conhecimentos essenciais para inserção do indivíduo na sociedade moderna. Assim, a articulação de conteúdos deve buscar a contextualização dos conhecimentos específicos, para que haja construção de significados, o que não é uma tarefa fácil, pois muitas vezes não se tem um entendimento claro de que em um determinado conteúdo científico estão inseridas 


\section{Ensino, Saúde e Ambiente - V 7 (1), Edição Especial, maio de 2014}

tantas informações de diferentes áreas. Isto torna o professor, como pesquisador de sua própria prática docente, responsável por fazer este tipo de transposição didática do conteúdo a ser aprendido, como também, trabalhar a contextualização daquilo que está sendo ensinado na Escola Básica. Essas questões podem ser inseridas num processo organizacional do currículo (MELLO, 2000).

Shulman (1986) destaca que é de grande importância que o professor em sua prática docente reflita sobre o conteúdo a ser ensinado, pois este pode influenciar no processo de abstração.

As Ciências Naturais e Exatas utilizam relações organizadas em princípios obtidos a partir de observação de fatos, seguindo-se experimentações, ou vice-versa. $\mathrm{O}$ ensino da Química na Escola Básica, quase sempre se faz de forma arbitrária, privilegiando a memorização automática e não significativa de pseudo-conceitos científicos (BRASIL, 1999). Pesquisas clássicas em educação científica tentam explicar estas tendências para a sala de aula de Química, concluindo que alunos não "visualizam" os fenômenos sobre os quais a Química, aparentemente, se fundamenta. Como o experimento em si não traz, muitas vezes, a ideia conceitual daquilo que se pretende ensinar, pois esta pode estar contaminada de termos muito distantes da realidade e percepção dos alunos, toda uma linguagem química é adequada, porém, respeitando a evolução de certos conceitos ainda não assimilados pelos estudantes.

Para Araújo (2002), a teoria e a prática não podem estar desvinculadas uma da outra, ou seja, a teoria deve estar subordinada a prática, apesar de que muitos estudiosos afirmam que não há prioridade entre esses dois termos (SERAFIM, 2001). Mas, por que a prática é tão importante no estudo da Ciência?

Segundo Terribili Filho (2009), uma pessoa em média, retém cerca de $20 \%$ daquilo que ouve, $30 \%$ daquilo que ouve e vê, e $50 \%$ do que ouve, vê e pratica. Deste modo, pode-se dizer que o homem armazena mais facilmente informações quando estas são advindas de estímulos visuais, sonoros e táteis, daí a importância da utilização dos sentidos humanos na aprendizagem. Deste modo, os recursos computacionais, tais como jogos e simuladores podem ser utilizados como mediadores instrumentais que visam à de maio de 2014. 


\section{Ensino, Saúde e Ambiente - V 7 (1), Edição Especial, maio de 2014}

contextualização da teoria e da prática de forma mais dinâmica, pois permitem uma maior interatividade entre o usuário e o conhecimento. Atualmente, observa-se o desenvolvimento de vários recursos computacionais para promover aprendizagens colaborativas e ativas, onde os usuários constroem sua própria interpretação sobre um dado assunto (PETITTO, 2003). No Banco Internacional de Objetos Educacionais, um repositório de recursos digitais com cunho pedagógico-educacional, que tem acesso no sítio: http://objetoseducacionais2.mec.gov.br/, encontram-se 345 simuladores, 195 áudios, 35 softwares, 496 vídeos, dentre outros recursos de Química para o Ensino Médio.

Assim, acredita-se que o desenvolvimento detalhado de uma ferramenta didática, mesmo que virtual, respeitando os parâmetros científicos, pode contribuir para a melhoria da qualidade do ensino e a motivação de um aprendizado significativo e coerente, levando o aluno a refletir sobre a importância dos conteúdos apresentados, bem como, interagir com o modelo proposto podendo tocá-lo, mesmo que virtual e entender um pouco do mundo microscópico.

\footnotetext{
A apreensão de novos saberes através das novas tecnologias deve ser contemplada e em sendo a escola o local por excelência da promoção de novas aprendizagens, faz-se necessário à inserção de ferramentas como os softwares de simulação em sua metodologia de ensino. (MELO; MELO, 2005, p. 54)
}

No entanto, segundo Heckler et al (2007) é importante que tanto alunos quanto professores tenham a ideia que o simulador é um modelo simplificado da realidade, para que não haja futuramente a concepção errônea do fenômeno que se está sendo estudado. Estas ferramentas didáticas permitem que o usuário manipule fenômenos complicados, perigosos ou demorados em poucos minutos, com muita segurança e repita quantas vezes quiser.

Deste modo, para o estudo da determinação da acidez e basicidade de substâncias cotidianas utilizando-se indicadores ácido-base, pensou-se que a criação de um simulador, cujo manuseio seria fácil e agradável, poderia ser útil para o entendimento do comportamento de ácidos e bases em solução, principalmente nas 


\section{Ensino, Saúde e Ambiente - V 7 (1), Edição Especial, maio de 2014}

escolas que não tem um laboratório. Porém, deve-se ressaltar que o professor ao utilizar um simulador como atividade didática, deve ter explorado todo o conteúdo para que as imagens observadas pelos alunos durante a execução do recurso possam fazer sentido para ele, tornando assim a aprendizagem deste conteúdo significativa e não simplesmente mecânica, isto é, permita que o aluno construa o seu próprio modelo mental e com isso possa fazer suas próprias inferências e previsões (MELO; MELO, 2005).

Para que as imagens que estão sendo utilizadas no material possam se tornar facilitadoras de aprendizagem, é necessário que o aluno não apenas olhe para elas e veja uma simples imagem, mas é preciso que o mesmo associe o texto aos dados informativos que esta lhe repassa, criando então diferentes relações e significados, auxiliando assim na construção de seu conhecimento. (HECKLER et al., 2007, p. 269)

Neste sentido, o simulador "Colorindo Bandeiras" (SOUZA; COUTINHO; CHACON, 2012) foi idealizado e desenvolvido por professores e alunos da Universidade Federal Fluminense (UFF), ligados ao Instituto de Química (IQ) e ao Instituto de Computação (IC), respectivamente. O software desenvolvido é uma ferramenta pedagógica onde se propõe a modificação da cor de um indicador através da adição de soluções ácida e básica. Entende-se que para uma melhor compreensão do processo é interessante discutir com os educandos o princípio básico das cores, como cor primária, cor secundária e o porquê das cores. É necessário também, o entendimento dos fenômenos de reflexão e absorção da luz.

Assim, este trabalho tem como principal objetivo apresentar e relatar a elaboração do simulador "Colorindo Bandeiras", que foi construído com recursos do Ministério da Educação e Cultura (MEC) e Ministério da Ciência e Tecnologia (MCT) no Projeto Condigital.

\section{METODOLOGIA}

A metodologia utilizada para a elaboração e desenvolvimento do recurso midiático incluiu:

$\checkmark \quad$ Estudo das principais características cognitivas do público alvo; 


\section{Ensino, Saúde e Ambiente - V 7 (1), Edição Especial, maio de 2014}

$\checkmark$ Determinação das metas a serem alcançadas com a utilização do recurso na Escola Básica;

$\checkmark$ Estudo de indicadores ácido-base e escolha das bandeiras;

$\checkmark$ Pesquisa bibliográfica sobre a história da bandeira de cada país escolhido;

$\checkmark$ Elaboração do layout da simulação a ser realizada;

$\checkmark$ Desenvolvimento do recurso pela equipe de desenvolvimento do Instituto de Computação da UFF;

$\checkmark$ Avaliação preliminar do recurso pela equipe idealizadora do Instituto de Química da UFF;

$\checkmark$ Elaboração de um guia do professor.

\section{RESULTADOS E DISCUSSÃO}

O Simulador "Colorindo Bandeiras", Figura 1, é indicado para alunos do Ensino Fundamental e Médio e visa fazer uma articulação da Química, com a História e a Geografia, pois através das cores das bandeiras pode o professor que é o mediador da aprendizagem estimular a aprendizagem sobre as cores dos indicadores ácido-base e sua importância no ensino da Química, ao mesmo tempo induzir o estudo sobre a história das bandeiras de países como a França, Portugal, Espanha e Brasil (SOUZA; COUTINHO; CHACON, 2012).

Figura 1: Tela inicial do Simulador.

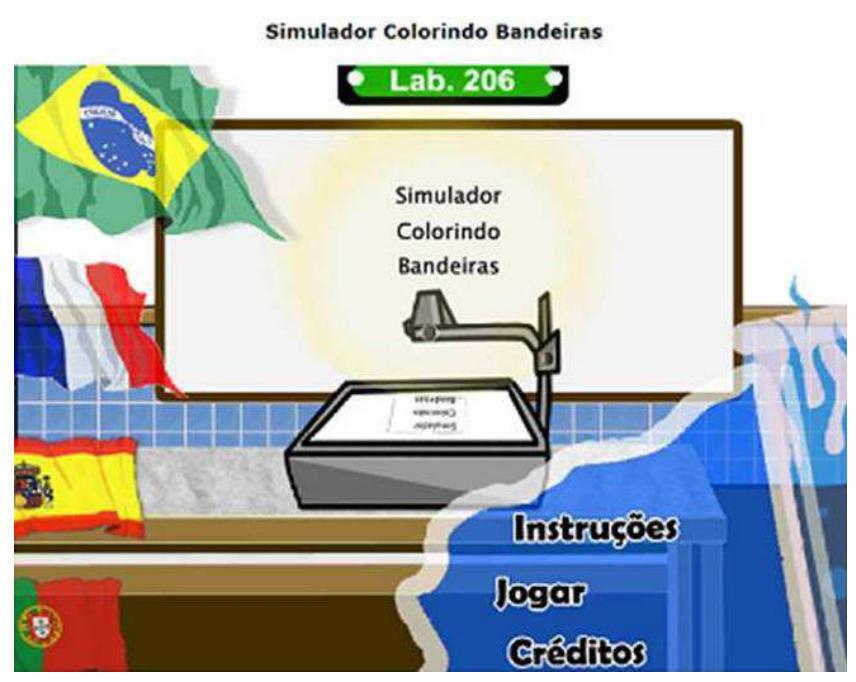

Fonte: Simulador “Colorindo Bandeiras” (SOUZA; COUTINHO; CHACON, 2012). 


\section{Ensino, Saúde e Ambiente - V 7 (1), Edição Especial, maio de 2014}

O desenvolvimento dos ensaios utilizados no simulador baseou-se no experimento do Professor Atílio José Vanin que coordenou o Grupo “Química em Ação" da USP, no qual acertam-se as cores da bandeira do Brasil usando o indicador Azul de Bromotimol em meio ácido e básico (MATEUS, REIS, PAULA, 2009). Este mesmo experimento é mostrado no livro Ciência na Tela: experimentos no retroprojetor, dos autores citados anteriormente. A partir deste ensaio, buscou-se a idealização de um experimento virtual que ao mesmo tempo fosse interessante, divertido, didático e ajudasse o professor a explorar o conteúdo "Indicadores ácido-base" em sala de aula, pois se entende que este tópico é de grande relevância dentro do estudo das interações químicas.

O recurso foi desenvolvido no Macromedia Flash 9, e necessita de uma versão mínima de navegador (browser) e de plug-in's previamente instalados, como o plug-in do Flash 9, plug-in Java (TM), Plug-in Version 1.4.1 e o Acrobat Reader. As ações necessárias para manipular o simulador são extremamente fáceis, podendo ser realizadas por qualquer indivíduo das mais diversas faixas etárias.

O objetivo do simulador é observar a mudança de cores de indicadores ácidobase, relacionando com o $\mathrm{pH}$ do meio e enfocar conceitos sobre essas interações, como: energia, acidez, basicidade, e outros, quando certas substâncias interagem entre si. A proposta de se fazer uma interface com um experimento virtual é facilitar a visualização dessas interações. No Simulador "Colorindo Bandeiras" (Figura 1) mostram-se as cores dos indicadores vermelho de fenol e azul de bromotimol em meio ácido ou básico, os quais foram usados para colorir as bandeiras de quatro países: França, Portugal, Espanha e Brasil.

$\mathrm{Na}$ segunda tela do simulador (Figura 2) observam-se a direita, bandeiras de quatro países, França, Portugal, Espanha e Brasil, com as cores trocadas e na bancada dois erlenmeyers contendo solução ácida e básica respectivamente. Nota-se também, o convite à realização do experimento virtual. No quadro branco observam-se instruções e comentários a respeito do experimento e da bandeira escolhida. 


\section{Ensino, Saúde e Ambiente - V 7 (1), Edição Especial, maio de 2014}

Figura 2: Tela 2 mostrando um convite a realização do experimento virtual.

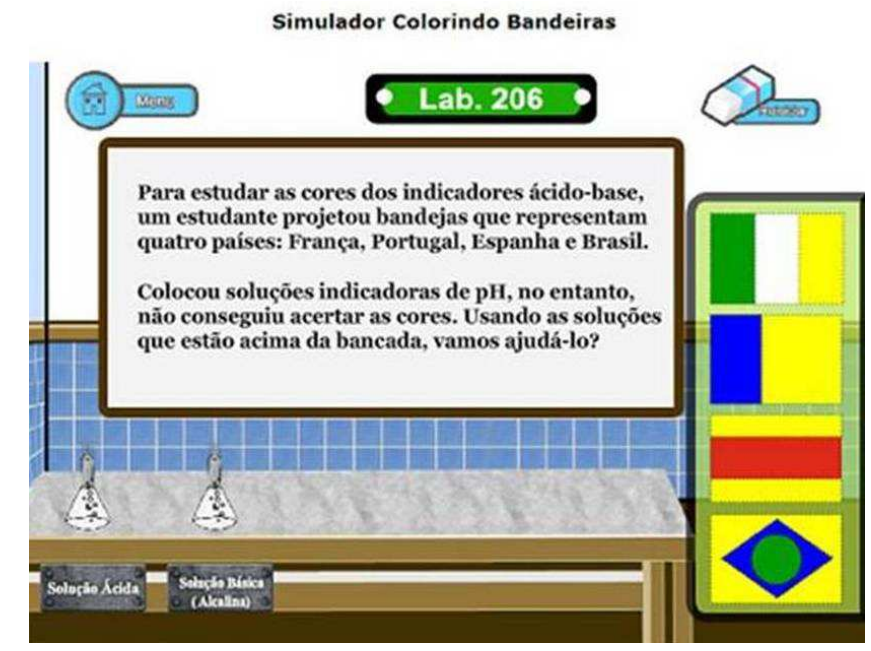

Fonte: Simulador “Colorindo Bandeiras” (SOUZA; COUTINHO; CHACON, 2012).

Ao clicar em uma das bandeiras, automaticamente ela virá para cima da bancada onde o aluno deverá acertar as cores adicionando solução ácida ou básica em cada compartimento, isto se dará através do arraste do erlenmeyer até cada uma das partes da bandeira (Figura 3).

Figura 3: Tela que aparece ao clicar na bandeira da França.

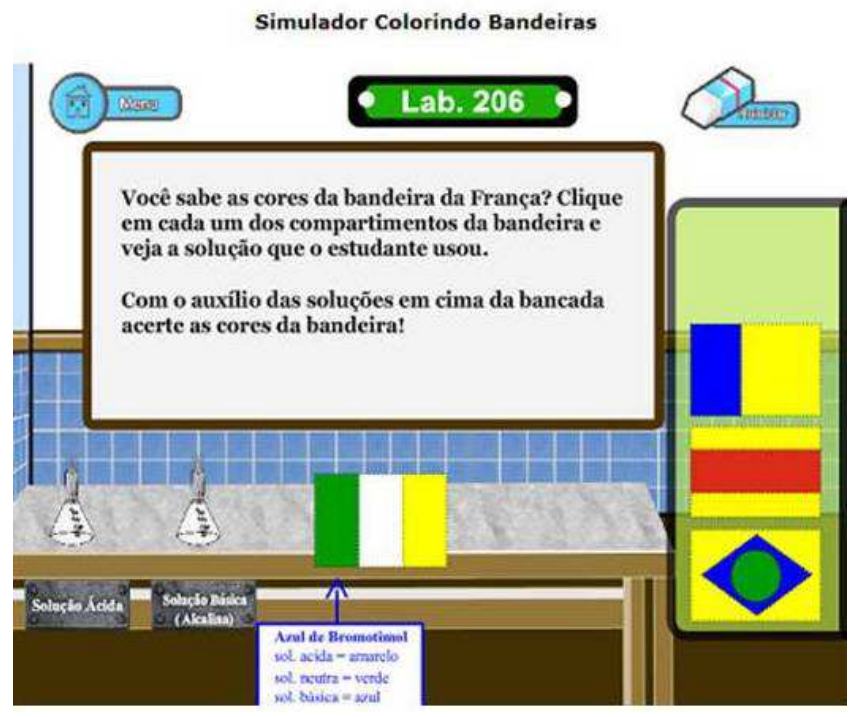

Fonte: Simulador “Colorindo Bandeiras" (SOUZA; COUTINHO; CHACON, 2012).

Mas como saber que solução adicionar? Ao clicar em cada compartimento da bandeira com a cor trocada aparecerá uma informação do indicador ácido-base utilizado 


\section{Ensino, Saúde e Ambiente - V 7 (1), Edição Especial, maio de 2014}

e sua coloração no meio básico, neutro ou ácido. A Figura 3 representa a terceira tela. Ao acertar as cores da bandeira do país, aparecerá uma mensagem no quadro branco com as informações e curiosidades a respeito da bandeira do respectivo país (Figura 4), onde se procurou articular a parte histórica e a localização geográfica do país que a bandeira representa. A simulação termina quando as cores da última bandeira forem acertadas.

Figura 4: Tela que aparece ao acertar as cores da bandeira da França.

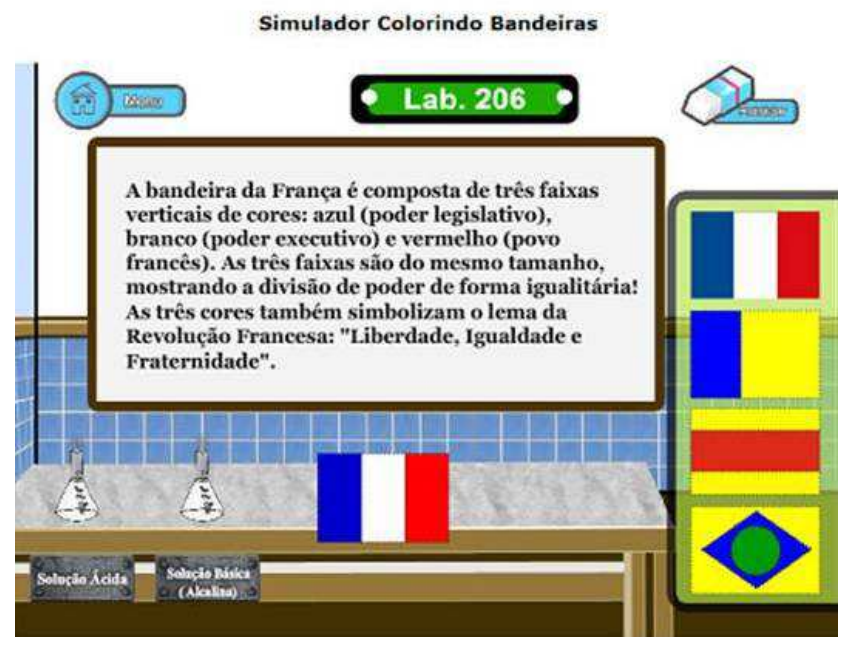

Fonte: Simulador "Colorindo Bandeiras" (SOUZA; COUTINHO; CHACON, 2012).

Para que professores e alunos possam tirar o maior proveito do recurso foi elaborado um guia do professor que além de explicar todo o funcionamento do simulador, dá dicas de como e quando utilizá-lo e do conhecimento básico necessário para o entendimento do assunto. O recurso está disponível no sitio do Banco Internacional de Recursos Educacionais, no endereço http://objetoseducacionais2.mec.gov.br/handle/mec/20032.

O simulador "Colorindo Bandeiras" ainda não foi avaliado por alunos da Escola Básica, mas ao ser apresentado a alguns alunos do Curso de Licenciatura da UFF, várias observações e comentários foram feitos, os quais contribuíram para o seu aprimoramento. Entende-se que o licenciando precisa ter ciência que será um futuro professor e que durante sua caminhada deverá procurar construir novas propostas de ensino, que em conjunto com os saberes aprendidos durante seu curso de graduação, 


\section{Ensino, Saúde e Ambiente - V 7 (1), Edição Especial, maio de 2014}

deverá aproximar conhecimentos disciplinares específicos aos conhecimentos pedagógicos. Assim, ele irá perceber que para ser um verdadeiro professor, dependerá destes saberes, que precisam ser (re)construídos.

Neste momento, chamou-se a atenção que a Química é uma Ciência com muito fascínio e que certas ferramentas educacionais tem o "poder" de transformar experimentos desenvolvidos em laboratórios em lúdico, despertando o visual desses experimentos e possibilitando assim, um melhor entendimento dos conceitos discutidos em aula.

Dentro dos comentários observados, destacaram-se algumas frases proferidas pelos alunos, conforme descrito a seguir:

A Química que é apresentada nas aulas teóricas é muito distante daquilo que se pode observar com o manuseio desse simulador, pois em aulas somente teóricas, não consigo ver quase nada de interessante que essa Ciência tem. (Aluno 1)

Não imaginava que se podia fazer alguma ponte entre a Química, História e Geografia. Achei também muito interessante acertarmos as cores das bandeiras quando gotejamos soluções dispostas na bancada, mostrada no Simulador e, a importância da parte histórica de cada bandeira do país sugerida. (Aluno 2)

\section{CONSIDERAÇÕES FINAIS}

Assim como outros recursos desenvolvidos atualmente, acredita-se que o simulador "Colorindo Bandeiras" pode auxiliar no ensino/aprendizagem da Química, mas, no entanto, ainda falta um estudo sistemático de como este recurso pode ajudar professores e alunos a enfrentarem as dificuldades pedagógicas inerentes ao estudo de indicadores ácido-base e as vantagens efetivas de sua aplicação na Escola Básica, o qual está sendo realizado e será relatado em outra oportunidade.

As primeiras análises do recurso mostraram uma boa receptividade por parte dos professores e alunos, no entanto, deve-se ressaltar, que como qualquer ferramenta didática o simulador desenvolvido necessita da atuação mediadora do professor, pois sem esta mediação a aprendizagem será puramente mecânica e o recurso perderá sua função principal que é promover uma integração entre o lúdico, a experimentação e a 
Ensino, Saúde e Ambiente - V 7 (1), Edição Especial, maio de 2014

contextualização. Fica evidente que a simples utilização do recurso por qualquer indivíduo não pode ser traduzida como uma aprendizagem significativa, pois durante a sua idealização e desenvolvimento não se pretendeu esgotar o assunto, muito menos criar um experimento virtual fantástico, mas objetivou-se através de ações simples trazer a tona a curiosidade sobre este relevante assunto.

\section{AGRADECIMENTOS}

Ao MEC/MCT e aos professores e alunos dos Institutos de Química e de Computação da UFF.

\section{REFERÊNCIAS}

ARAUJO, R. M. L. A Articulação Teoria e Prática nas Políticas de Formação dos Professores para a Educação Básica: a competência como ferramenta para a formação do professor prático. Revista ver a Educação. 8(2), p. 65-78, 2002.

BRASIL, Ministério da Educação (MEC), Secretaria de Educação Média e Tecnológica (Semtec). Parâmetros Curriculares Nacionais para o Ensino Médio. Brasília: MEC/ Semtec, 1999.

HECKLER, V.; SARAIVA, M. F. O.; OLIVEIRA FILHO, K. S. Uso de simuladores, imagens e animações como ferramentas auxiliares no ensino/aprendizagem de óptica. Revista Brasileira de Ensino de Física, 29(2), p. 267-273, 2007.

MATEUS, A. L.; REIS, D. A.; PAULA, H. F. Ciência na tela: experimentos no retroprojetor. Belo Horizonte: Editora UFMG, 2009.

MELLO, G. N. Formação Inicial de Professores para a Educação Básica: uma (re)visão radical. Revista São Paulo em Perspectiva, 14(1), 2000. Disponível em: http://dx.doi.org/10.1590/S0102-88392000000100012. Acessado em 05/02/2014.

MELO, E. S. N.; MELO, J. R. F. Softwares de simulação no ensino de química: uma representação social na prática docente. ETD - Educação Temática Digital, Campinas, 6(2), p.51-63, 2005. Disponível em

http://www.fae.unicamp.br/revista/index.php/etd/article/view/1656/1502. Acessado em 06/02/2014.

PETITTO, S. Projetos de Trabalho em Informática: Desenvolvendo Competências. Campinas: Papirus, 2003.

SERAFIM, M. C. A falácia da dicotomia Teoria-Prática. Revista Espaço Acadêmico, Ano I, $N^{\mathrm{o}}$ 07, 2001. 
Ensino, Saúde e Ambiente - V 7 (1), Edição Especial, maio de 2014

SHULMAN, L. Those who understand: the knowledge growths in teaching. In:

Education Research, 15(2), 1986. Disponível em http://www.jstor.org/stable/1175860. Acessado em 05/02/2014.

SOUZA, N. A.; COUTINHO, L. G. R.; CHACON, E. P. Simulador Colorindo Bandeiras. 2012. Disponível em

http://objetoseducacionais2.mec.gov.br/handle/mec/20032. Acessado em 05/02/2014.

TERRIBILI FILHO, A. T. El profesor como investigador: ¡acción ya! Revista Q Revista electrónica de divulgación académica y científica de las investigaciones sobre la relación entre Educación, Comunicación y Tecnología, 4(7), 2009.

Disponível em http://eav.upb.edu.co/RevQ/articulos/descargar/265/pdf. Acessado em 04/02/2014. 